\title{
Effects of oxidised dietary fish oil and high-dose vitamin E supplementation on growth performance, feed utilisation and antioxidant defence enzyme activities of juvenile large yellow croaker (Larmichthys crocea)
}

\author{
Jun Wang ${ }^{1,2}$, Houguo $\mathrm{Xu}^{1}$, Rantao Zuo ${ }^{1}$, Kangsen $\mathrm{Mai}^{1}$, Wei $\mathrm{Xu}^{1}$ and Qinghui $\mathrm{Ai}^{1 *}$ \\ ${ }^{1}$ The Key Laboratory of Mariculture, Ministry of Education of China, Ocean University of China, 5 Yushan Road, Qingdao, \\ Shandong 266003, People's Republic of China \\ ${ }^{2}$ Present address: The Key Laboratory of Aquatic Product Processing, Ministry of Agriculture, South China Sea Fisheries \\ Research Institute, Chinese Academy of Fishery Sciences, 231 Xingang Road, Guangzhou, Guangdong 510300, People's \\ Republic of China
}

(Submitted 12 June 2015 - Final revision received 19 December 2015 - Accepted 20 January 2016 - First published online 7 March 2016)

\section{Abstract}

This study was conducted to elucidate the effects of oxidised dietary lipids and high-dose vitamin E (VE) on growth performance and immune responses of large yellow croaker. Juvenile fish (initial average body weight of 7.82 (SEM 0.68) g) were fed diets containing either fresh fish oil (fresh diet, peroxide value $(\mathrm{POV})=1.72 \mathrm{mEq} / \mathrm{kg}$ ) or fish oil oxidised to varying degrees (oxidised diets, $\mathrm{POV}=28 \cdot 29-104 \cdot 21 \mathrm{mEq} / \mathrm{kg}$ ), with or without supplementary $600 \mathrm{mg}$ VE/kg diet, for 10 weeks in floating cages. Growth was significantly lower and feed intake (g/100 g body weight per d) was higher in fish fed the oxidised diet. Supplementation with VE increased the growth of fish fed the oxidised diets, but significantly decreased the growth of fish fed the fresh diet. Hepatosomatic index increased with increasing dietary POV and decreased with VE supplementation. Hepatic catalase activity, superoxide dismutase (SOD) activity and malondialdehyde content were significantly higher in fish fed the oxidised diets, and these values decreased significantly following VE supplementation. However, hepatic SOD activity was enhanced by VE supplementation in fish fed the fresh diet. Air-exposure mortality was significantly increased by dietary POV, and this effect was inhibited by VE supplementation. These results suggest that dietary oxidised fish oil could stimulate the activities of antioxidant defence enzymes in stressed large yellow croaker. High-dose VE supplementation can alleviate oxidative stress of large yellow croaker fed oxidised fish oil, but can exert deleterious effects on fish in the absence of oxidative stress.

\section{Key words: Large yellow croaker: Larmichthys crocea: Oxidised fish oil: Vitamin E: Oxidative stress}

Fish oil contains high amounts of $n-3$ highly unsaturated fatty acids (HUFA) such as EPA (20:5n-3) and DHA (22:6n-3), which are essential to many marine fish species because of deficiencies in the desaturation and elongation pathways necessary for their biosynthesis ${ }^{(1,2)}$. However, fatty acids are particularly susceptible to oxidation during feed processing and storage, especially in the absence of adequate amounts of antioxidants $^{(3)}$. Oxidised fish oil is harmful to fish ${ }^{(4-6)}$.

Vitamin E (VE) is one of the most extensively used antioxidants in foods and has been shown to reduce oxidative stress in fish ${ }^{(6-11)}$. A higher dose of VE is required in fish diets, particularly those with high levels of HUFA, because dietary lipid oxidation can reduce the VE content ${ }^{(7,12,13)}$. Moreover, several times the optimum dietary VE level is needed to enhance the non-specific immune responses of fish $^{(14)}$. However, high doses of VE may exert pro-oxidative effects on human LDL and lipids in fish tissues ${ }^{(15-17)}$.
In commercial situations, diets are often stored at room temperature for long periods of time, resulting in the oxidation of dietary lipids to varying degrees. Many previous studies have supplemented diets containing identical lipid oxidation values with graded levels of VE to evaluate optimal dietary VE concentrations under conditions of oxidative stress ${ }^{(4,6,8,11,18,19)}$. However, there is a lack of information with respect to the effects of VE under conditions of varying degrees of oxidative stress. The effects of the severity of oxidative stress on the role of dietary VE in marine fish are unclear.

Large yellow croaker (Larmichthys crocea) is a major commercially important marine fish in China and has been widely cultured in recent years. As a carnivorous species, its dietary lipid content is relatively high ${ }^{(20)}$. In subtropical and tropical regions such as southeast China, the climate is humid and the temperature is relatively high throughout the year, especially during the summer. Under such climatic conditions, it is probable that dietary

Abbreviations: AEM, air-exposure mortality; CAT, catalase; FFO, fresh fish oil; FI, feed intake; HO, highly oxidised; LO, lowly oxidised; MDA, malondialdehyde; MO, moderately oxidised; POV, peroxide value; SOD, superoxide dismutase; VE, vitamin E.

* Corresponding author: Q. Ai, fax +86 5328203 1943, email qhai@ouc.edu.cn 
lipids would be easily oxidised to different degrees depending upon the conditions under which the diets are stored.

Therefore, in the present study, graded oxidative stress in juvenile large yellow croaker was induced by feeding diets in which the fish oil was oxidised to various degrees. High-dose ( $600 \mathrm{mg} / \mathrm{kg}$ diet) VE was supplemented in the diet to determine the effects on growth performance, activities of hepatic antioxidant defence enzymes and head kidney macrophages respiratory burst activity of fish suffering various stressful conditions. The purpose of this study was to investigate the combined effects of variable degrees of lipid oxidation and highdose VE supplementation on oxidative-stressed marine fish.

\section{Methods}

\section{Diet preparation}

White fishmeal and menhaden fish oil without antioxidant were used as the main protein and lipid sources in the diet (Table 1). The peroxide value (POV) of fresh fish oil (FFO) was $1.72 \mathrm{mEq} / \mathrm{kg}$. FFO was oxidised to three different degrees (low, moderate and high) by heating at $50{ }^{\circ} \mathrm{C}$ with vigorous aeration while monitoring the POV at 4 -h intervals. The final POV values for the lowly (LO), moderately (MO) and highly oxidised (HO) fish oil were $28.29,62.79$ and $104.21 \mathrm{mEq} / \mathrm{kg}$, respectively.

Table 1. Formulation of the experimental basal diet

\begin{tabular}{|c|c|}
\hline Ingredients & $\%$ \\
\hline Fishmeal* $^{*}$ & $43 \cdot 0$ \\
\hline Soyabean meal* & $15 \cdot 0$ \\
\hline Fish oil* & $7 \cdot 0$ \\
\hline Beer yeast ${ }^{\star}$ & $3 \cdot 0$ \\
\hline Wheat meal & $25 \cdot 3$ \\
\hline Lecithin & 2.5 \\
\hline Attractant $†$ & 0.3 \\
\hline Mould inhibitor $\ddagger$ & 0.1 \\
\hline Vitamin premix§ & $2 \cdot 0$ \\
\hline Mineral premixll & $2 \cdot 0$ \\
\hline
\end{tabular}

* Fishmeal obtained from Russia AKROS Fishing Co. Ltd; soyabean meal obtained from Liulu Oli Lit; fish oil obtained from Shengda Fish Meal \& Oil Co. Ltd; beer yeast obtained from Cishan Fisheries.

$\dagger$ Attractant: glycine and betaine.

¥ Mould inhibitor contained $50 \%$ calcium propionic acid and $50 \%$ fumaric acid.

$\S$ Vitamin premix ( $\mathrm{mg}$ or g/kg diet): thiamin, $25 \mathrm{mg}$; riboflavin, $45 \mathrm{mg}$; pyridoxine $\mathrm{HCl}$ $20 \mathrm{mg}$; vitamin $\mathrm{B}_{12}, 0.1 \mathrm{mg}$; vitamin $\mathrm{K}_{3}, 10 \mathrm{mg}$; inositol, $800 \mathrm{mg}$; pantothenic acid, $60 \mathrm{mg}$; niacin acid, $200 \mathrm{mg}$; folic acid, $20 \mathrm{mg}$; biotin, $1.20 \mathrm{mg}$; retinyl acetate, $32 \mathrm{mg}$; cholecalciferol, $5 \mathrm{mg}$; DL-a-tocopherol, $120 \mathrm{mg}$; ascorbic acid, $2000 \mathrm{mg}$; choline chloride, $2500 \mathrm{mg}$; microcrystalline cellulose, $14.67 \mathrm{~g}$.

|| Mineral premix (mg or g/kg diet): NaF, $2 \mathrm{mg} ; \mathrm{Kl}, 0.8 \mathrm{mg} ; \mathrm{CoCl}_{2} .6 \mathrm{H}_{2} \mathrm{O}(1 \%), 50 \mathrm{mg}$; $\mathrm{CuSO}_{4} .5 \mathrm{H}_{2} \mathrm{O}, 10 \mathrm{mg} ; \mathrm{FeSO}_{4} \cdot \mathrm{H}_{2} \mathrm{O}, 80 \mathrm{mg} ; \mathrm{ZnSO}_{4} \cdot \mathrm{H}_{2} \mathrm{O}, 50 \mathrm{mg} ; \mathrm{MnSO}_{4} \cdot \mathrm{H}_{2} \mathrm{O}, 60 \mathrm{mg}$ $\mathrm{MgSO}_{4} \cdot 7 \mathrm{H}_{2} \mathrm{O}, 1200 \mathrm{mg} ; \mathrm{Ca}\left(\mathrm{H}_{2} \mathrm{PO}_{3}\right)_{2} \cdot \mathrm{H}_{2} \mathrm{O}, 3000 \mathrm{mg} ; \mathrm{NaCl}, 100 \mathrm{mg}$; zoelite, $15.45 \mathrm{~g}$.
After oxidisation, diets containing either fresh or oxidised fish oil were stabilised with $150 \mathrm{mg}$ ethoxyquin $/ \mathrm{kg}$ diet. The proximate composition of the experimental diets is shown in Table 2 .

A previous study in our laboratory demonstrated that approximately $60 \mathrm{mg}$ DL- $\alpha$-tocopheryl acetate ( $\alpha$-Toc)/kg diet was adequate to maintain normal physiological function in juvenile large yellow croaker ${ }^{(21)}$. In the present study, eight experimental diets were designed to investigate the effects of $600 \mathrm{mg} / \mathrm{kg} \mathrm{VE}$ $(\alpha$-Toc) and oxidised fish oil (LO, MO and HO) on large yellow croaker: two FFO diets (FFO and FFO/VE), two LO fish oil diets (LO and LO/VE), two MO fish oil diets (MO and MO/VE) and two $\mathrm{HO}$ fish oil diets ( $\mathrm{HO}$ and $\mathrm{HO} / \mathrm{VE}$ ). Experimental diets were sealed in plastic bags and stored indoors in wooden boxes at room temperature until use. Samples were taken from these diets and stored at $-20^{\circ} \mathrm{C}$ for future chemical determinations.

\section{Experimental procedures}

Fish rearing and sampling were carried out according to the experimental procedures of the key laboratory of mariculture (Ministry of Education of China), Ocean University of China. Juvenile large yellow croaker $L$. crocea was obtained from a local commercial hatchery farm in Xiangshan Bay, Ningbo, China. Upon arrival, they were reared in open floating sea cages $(3.0 \times 3.0 \times 3.0 \mathrm{~m})$ and were fed the control diet for 2 weeks to acclimate to the experimental diet and culture conditions. At the end of the acclimatisation period, the fish were starved for $24 \mathrm{~h}$, anaesthetised with eugenol (1:10000; Shanghai Reagent) and weighed. Fish of similar sizes (7.82 (SEM 0.68) g) were distributed into twenty-four sea cages $(1.5 \times 1.5 \times 2.0 \mathrm{~m})$, and each cage was stocked with sixty fish. Each diet was randomly assigned to triplicate cages. The fish were hand-fed to apparent satiation twice daily (04.30 and 16.30 hours). Fish were considered satiated when they did not exhibit feeding behaviour towards the pellets. The weight of diet for each cage before feeding was recorded and the remaining diet was weighed. Daily consumption of feed in each cage was recorded. Smaller pellets $(1.5 \mathrm{~mm})$ were fed to fish during weeks 1-4 and the larger pellets $(2.5 \mathrm{~mm})$ during weeks $5-10$. The feeding trial lasted for 10 weeks. Water column characteristics were monitored weekly in the morning. During the trial, water temperature ranged from 26.5 to $29.5^{\circ} \mathrm{C}$, the salinity was about $28 \mathrm{~g} / \mathrm{l}$ and dissolved $\mathrm{O}_{2}$ content was approximately $7 \mathrm{mg} / \mathrm{l}$.

\section{Biochemical analysis}

Fish were starved for $24 \mathrm{~h}$ at the end of the feeding trial. The total number and mean body weight of the fish in each cage were measured. Ten fish were randomly sampled from each cage for

Table 2. Proximate composition of the experimental diets (\%, dry weight basis)

\begin{tabular}{|c|c|c|c|c|c|c|c|c|}
\hline \multirow[b]{2}{*}{ Proximate composition (\%) } & \multicolumn{8}{|c|}{ Diets } \\
\hline & FFO & FFO/VE & LO & LO/VE & MO & MO/VE & $\mathrm{HO}$ & HO/VE \\
\hline Crude protein & 43.4 & 43.4 & $43 \cdot 6$ & 43.9 & 43.8 & 43.5 & $43 \cdot 7$ & 43.9 \\
\hline Crude lipid & $12 \cdot 9$ & $13 \cdot 1$ & $12 \cdot 9$ & $13 \cdot 3$ & $13 \cdot 1$ & $13 \cdot 0$ & $12 \cdot 7$ & $13 \cdot 2$ \\
\hline Ash & $12 \cdot 4$ & $12 \cdot 4$ & $13 \cdot 8$ & $14 \cdot 1$ & $13 \cdot 6$ & $14 \cdot 1$ & $14 \cdot 0$ & $14 \cdot 3$ \\
\hline Analysed $a$-Toc (mg/kg) & $108 \cdot 2$ & 681.9 & $112 \cdot 0$ & $689 \cdot 3$ & $102 \cdot 9$ & $701 \cdot 3$ & $110 \cdot 8$ & 695.8 \\
\hline
\end{tabular}

FFO, fresh fish oil; VE, vitamin E; LO, lowly oxidised fish oil; MO, moderately oxidised fish oil; HO, highly oxidised fish oil; $a$-Toc, DL- $a$-tocopheryl acetate. 
individual proximate composition analysis. Proximate composition analyses of feed ingredients, experimental diets and fish carcass were performed according to the standard methods ${ }^{(22)}$. Samples of the diets and fish were dried to a constant weight at $105^{\circ} \mathrm{C}$ to determine moisture content. Protein content was determined by measuring $\mathrm{N}$ content $(\mathrm{N} \times 6.25)$ using the Kjeldahl method. Body lipid levels were quantified by diethyl ether extraction using Soxhlet. Lipids in the liver were extracted as described by Folch et al. ${ }^{(23)}$. Ash was measured by combustion at $550^{\circ} \mathrm{C}$. All measurements and determinations were performed in triplicate. Fatty acid profiles were analysed using a HP6890 GC (Agilent Technologies Inc.) as described by Zuo et $a l{ }^{(24)}$. The $\alpha$-Toc concentrations of diets were determined by HPLC with a fluorescence detector according to Salo-Väänänena et $a l^{(25)}$.

\section{Antioxidant enzyme activity and respiratory burst activity}

Blood samples were collected from the caudal vein from three fish per cage with a $27-\mathrm{G}$ needle and a $1-\mathrm{ml}$ syringe, allowed to clot at room temperature for $4 \mathrm{~h}$ and then at $4^{\circ} \mathrm{C}$ for further $6 \mathrm{~h}$. Following centrifugation $\left(836 \mathbf{g}, 10 \mathrm{~min}, 4^{\circ} \mathrm{C}\right)$, serum samples were immediately frozen in liquid $\mathrm{N}_{2}$ and stored at $-80^{\circ} \mathrm{C}$ for later analysis of antioxidant defence enzyme activities. Activities of superoxide dismutase (SOD) and catalase (CAT) were determined using commercial kits (Nanjing Jiancheng Bioengineering Institute) following the manufacturer's protocol. Respiratory burst activity of head kidney macrophages was measured according to a method previously described in our laboratory by Zuo et al. ${ }^{(24)}$.

\section{Hepatic malondialdehyde}

Livers were dissected from three fish per cage, immediately frozen in liquid $\mathrm{N}_{2}$ and stored at $-80^{\circ} \mathrm{C}$ before analysis. Malondialdehyde (MDA), one of the metabolites derived from lipid peroxidation, was measured using a thiobarbituric acid reactive substances assay kit (Nanjing Jiancheng Bioengineering Institute) following the manufacturer's protocol.

\section{Air-exposure mortality}

After blood and tissue sampling, twenty fish were randomly collected from each cage, exposed to air at an ambient temperature of approximately $28^{\circ} \mathrm{C}$ for $12 \mathrm{~min}$ and then put back into the water. Accumulated mortality during the subsequent $20 \mathrm{~min}$ was monitored and was defined as air-exposure mortality (AEM).

\section{Calculations and statistical analysis}

The following variables were calculated:

$$
\begin{aligned}
& \text { Survival }(\%)=100 \times N_{\mathrm{t}} / N_{0}, \\
& \text { Specific growth rate }(\mathrm{SGR}, \% / \mathrm{d})=100 \times\left(\ln W_{t}-\ln W_{0}\right) / t, \\
& \text { Feed intake }(\mathrm{FI}, \mathrm{g} / 100 \mathrm{gBW} / \mathrm{d})=D_{f} \times 100 /\left(\left(W_{t}+W_{0}\right) / 2 \times t\right), \\
& \text { Feed efficiency }(\mathrm{FE})=\left(W_{t}-W_{0}\right) / D_{f}, \\
& \text { Hepatosomatic index }(\mathrm{HSI}, \%)=100 \times \text { liver wet weight } / W_{t},
\end{aligned}
$$

where $N_{0}$ and $N_{t}$ represent the initial and final numbers of fish in each cage, respectively. BW is the wet body weight, $W_{t}$ is the final mean body weight $(\mathrm{g}), W_{0}$ is the initial mean body weight $(\mathrm{g}), t$ is the experimental duration in days and $D_{f}$ is the dry diet intake $(\mathrm{g})$.

All data were subjected to a one-way ANOVA test, and differences between the means were tested by Tukey's multiple-range test. The level of significance was set at $P<0.05$, and the results are presented as mean values with their standard errors. All the statistical analyses were performed using Statistica 6.0 (StatSoft).

\section{Results \\ Dietary fatty acid profiles}

Lipid oxidation increased the proportions of SFA and MUFA fatty acids, and decreased the proportions of EPA, DHA and total HUFA in the experimental diets (Table 3).

\section{Survival, growth, feed utilisation and hepatosomatic index}

There were no significant differences $(P>0.05)$ in the rate of survival, which ranged from 93.7 to $97.5 \%$, among the treatments (Fig. 1(A)). For the VE non-supplemented groups, the specific growth rate was significantly $(P<0.05)$ lower in fish fed the oxidised diets than in fish fed the FFO diet. VE supplementation significantly $(P<0.05)$ decreased the growth rate of fish fed FFO. However, VE supplementation increased the growth rate of fish fed the oxidised diets (Fig. 1(B)).

FI of fish fed MO and $\mathrm{HO}$ were significantly $(P<0.05)$ higher than fish fed FFO and LO. VE supplementation increased the FI of fish fed FFO and LO, but decreased the FI of fish fed MO and $\mathrm{HO}$ (Fig. $1(\mathrm{C})$ ). No statistically significant differences $(P>0.05)$ were detected in FE between treatments (Fig. 1(D)). The hepatosomatic index (HSI) of fish increased with increasing dietary POV and decreased with VE supplementation. The HSI

\begin{tabular}{|c|c|c|c|c|}
\hline & \multicolumn{4}{|c|}{ Diets } \\
\hline & $\begin{array}{l}\text { Fresh } \\
\text { fish oil }\end{array}$ & $\begin{array}{l}\text { Lowly } \\
\text { oxidised fish } \\
\text { oil }\end{array}$ & $\begin{array}{l}\text { Moderately } \\
\text { oxidised fish oil }\end{array}$ & $\begin{array}{c}\text { Highly } \\
\text { oxidised fish } \\
\text { oil }\end{array}$ \\
\hline C16:0 & 20.07 & $20 \cdot 02$ & $20 \cdot 68$ & 20.97 \\
\hline C18:0 & $3 \cdot 36$ & $3 \cdot 37$ & $3 \cdot 46$ & 3.52 \\
\hline C20:0 & $5 \cdot 14$ & 5.25 & 5.32 & 5.37 \\
\hline$\Sigma$ SFA & 28.58 & $28 \cdot 64$ & $29 \cdot 46$ & 29.86 \\
\hline C16:1 & $6 \cdot 81$ & $6 \cdot 82$ & 7.06 & $7 \cdot 16$ \\
\hline C18: $1 n-7$ & $10 \cdot 05$ & $10 \cdot 18$ & $10 \cdot 36$ & 10.53 \\
\hline C18:1n-9 & $2 \cdot 38$ & 2.42 & 2.44 & 2.47 \\
\hline$\Sigma$ MUFA & $19 \cdot 23$ & $19 \cdot 42$ & 19.87 & $20 \cdot 15$ \\
\hline C18:2n-6 & 1.98 & 1.97 & 1.96 & 1.98 \\
\hline C18:3n-3 & 1.35 & 1.33 & 1.30 & 1.31 \\
\hline $\mathrm{C} 20: 5 n-3$ (EPA) & 0.61 & 0.60 & 0.57 & 0.57 \\
\hline $\mathrm{C} 22: 6 n-3(\mathrm{DHA})$ & $9 \cdot 70$ & 9.54 & $8 \cdot 84$ & 8.91 \\
\hline$\Sigma$ HUFA & $10 \cdot 31$ & $10 \cdot 14$ & 9.41 & 9.48 \\
\hline
\end{tabular}
of fish in the HO group was significantly higher $(P<0.05)$ than in the HO/VE group (Fig. 1(E)).

Table 3. Fatty acid composition (\% total fatty acids) of the experimental diets containing different levels of oxidised fish oil

HUFA, highly unsaturated fatty acids (EPA and DHA in the present study). 
(A)

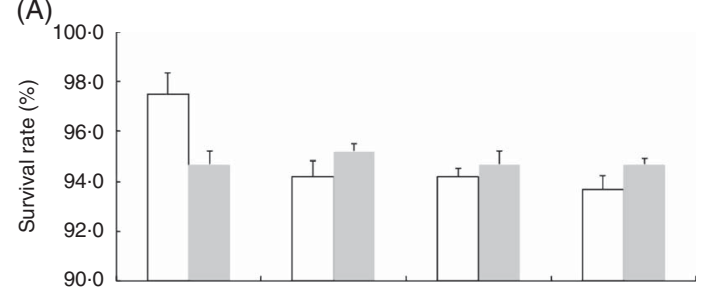

(B)

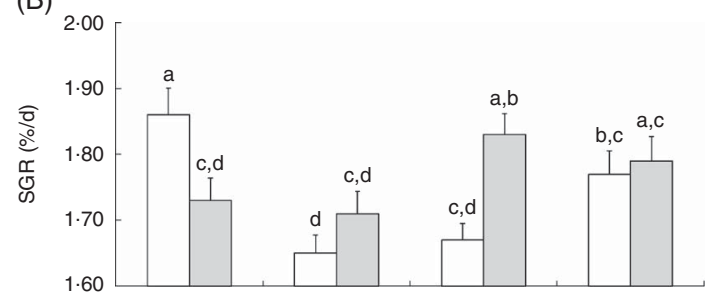

(C)

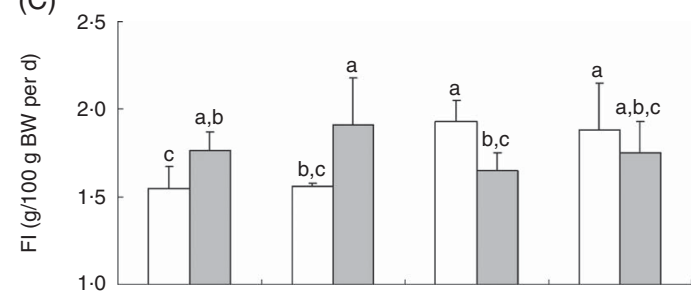

(D)

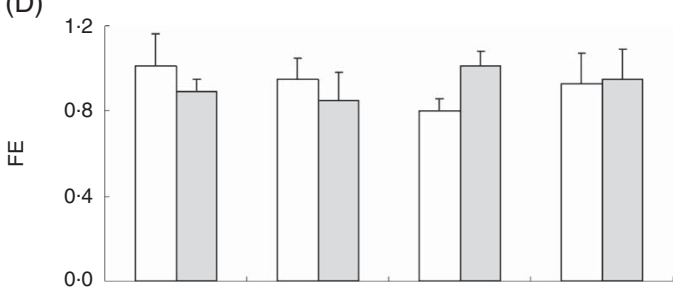

(E)

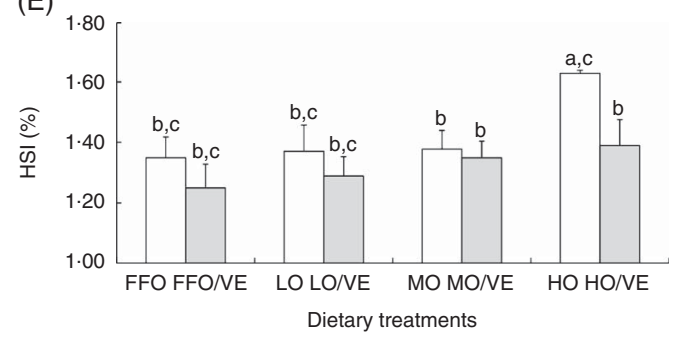

Fig. 1. Survival rate $(A)$, specific growth rate (SGR) $(B)$, feed intake $(F I)$ $(C)$, feed efficiency $(F E)(D)$ and hepatosomatic index $(\mathrm{HSI})(\mathrm{E})$ of juvenile large yellow croaker fed diets containing oxidised fish oil supplemented with vitamin $E(V E)$ for 10 weeks. Values are means, with their standard errors represented by vertical bars. ${ }^{a, b, c, d}$ Mean values with unlike letters were not significantly different $(P>0.05)$ among treatments. BW, body weight; FFO, fresh fish oil; LO, lowly oxidised; MO, moderately oxidised; HO, highly oxidised.

\section{Body composition}

No statistically significant differences $(P>0.05)$ in whole-body composition were detected among treatments, with the exception of lipid content $(P<0.05)$. Fish fed the oxidised diets had a lower lipid content than fish fed FFO, and their lipid content increased with VE supplementation. Dietary inclusion of VE increased lipid content in the liver of fish in all the groups, with significant differences detected in fish fed FFO and LO diets $(P<0.05)$ (Table 4).

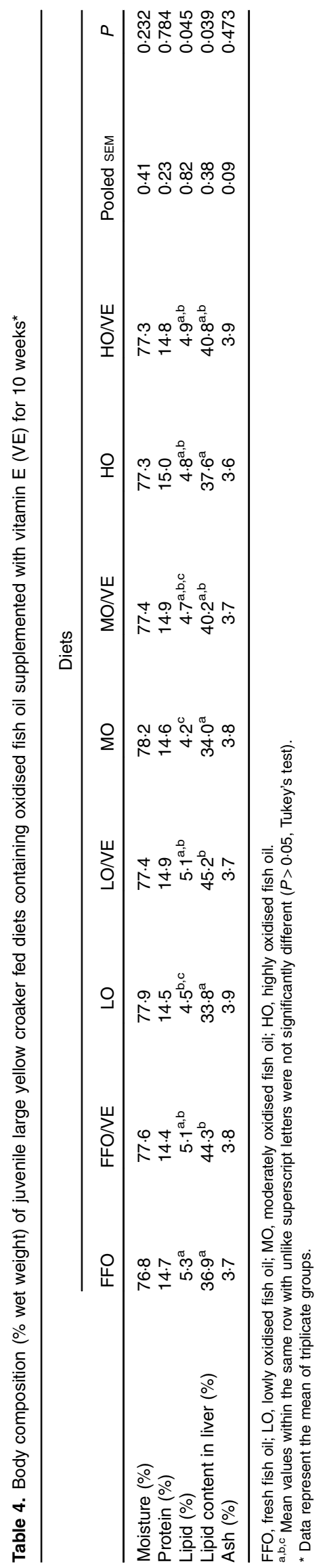


(A)

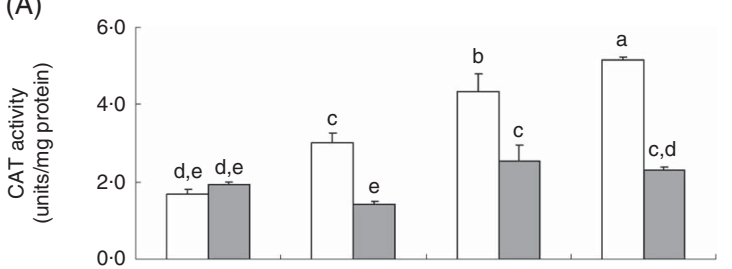

(B)

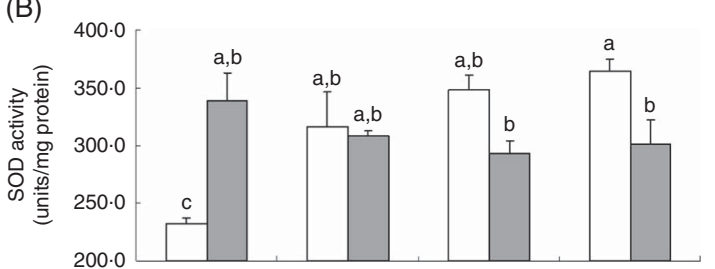

(C)

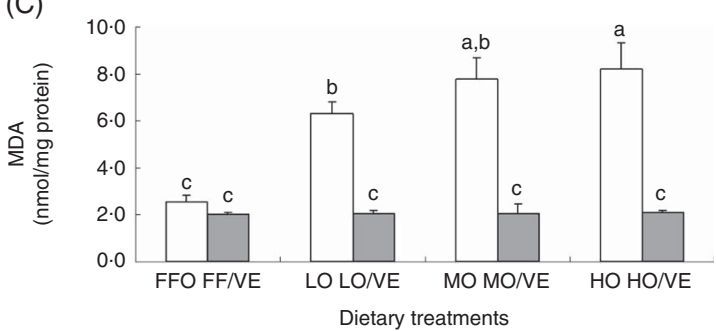

Fig. 2. Hepatic catalase (CAT) activity (A), superoxide dismutase (SOD) activity $(B)$ and malondialdehyde (MDA) content (C) of juvenile large yellow croaker fed diets containing oxidised fish oil supplemented with vitamin $E(V E)$ for 10 weeks. Values are means, with their standard errors represented by vertical bars. ${ }^{a, b, c, d, e}$ Mean values with unlike letters were not significantly different $(P>0.05)$ among treatments. FFO, fresh fish oil; LO, lowly oxidised; $\mathrm{MO}$, moderately oxidised; $\mathrm{HO}$, highly oxidised.

\section{Antioxidant enzyme activities and respiratory} burst activities

As dietary POV increased in the groups not supplemented with VE, the activities of CAT and SOD increased significantly $(P<0 \cdot 05)$. VE supplementation significantly $(P<0 \cdot 05)$ reduced the activities of CAT and SOD in fish fed the oxidised diets. In contrast, the activities of CAT and SOD were increased by VE supplementation in fish fed the FFO diet (Fig. 2(A) and (B)). Hepatic MDA levels increased significantly $(P<0.05)$ with each increase in dietary POV (Fig. 2(C)). VE supplementation decreased the concentration of MDA in all groups, irrespective of dietary POV. No significant $(P>0.05)$ differences in MDA concentration were observed among the VE supplementation groups (Fig. 2(C)).

No significant $(P>0.05)$ difference in respiratory burst activities (optical density 630 values) was detected among treatments, although fish fed oxidised diets had lower respiratory burst activities than those fed FFO (Fig. 3).

\section{Air-exposure mortality}

AEM increased significantly $(P<0.05)$ with increasing dietary POV (Fig. 4). VE supplementation decreased AEM in fish fed oxidised diets and increased AEM in fish fed FFO. The positive

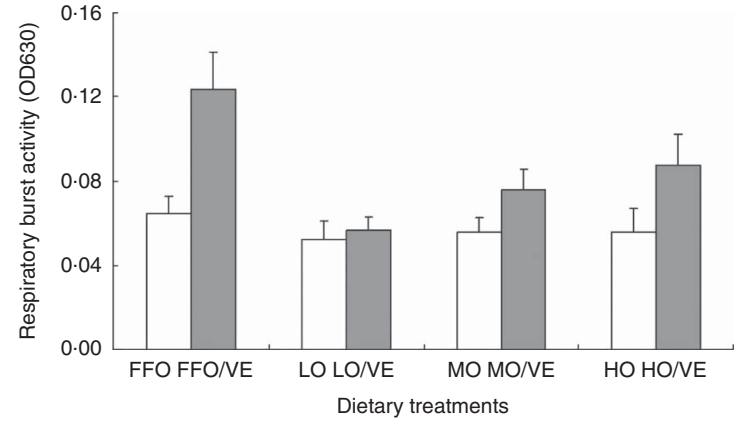

Fig. 3. Respiratory burst activity of head kidney macrophages from juvenile large yellow croaker fed diets containing oxidised fish oil supplemented with vitamin $E(V E)$ for 10 weeks. Values are means, with their standard errors represented by vertical bars. OD, optical density; FFO, fresh fish oil; LO, lowly oxidised; MO, moderately oxidised; $\mathrm{HO}$, highly oxidised.

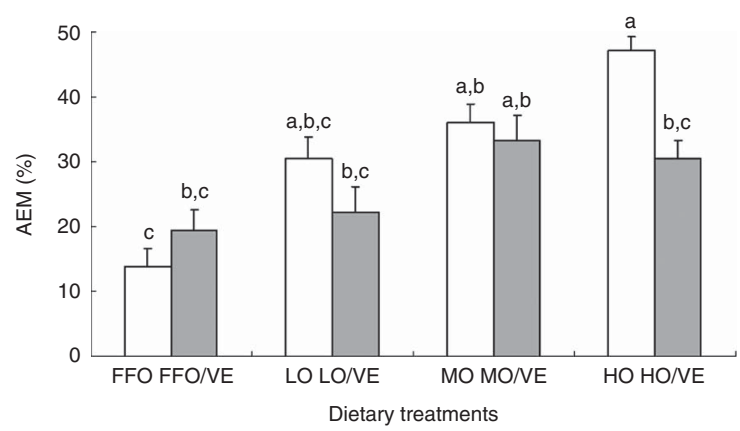

Fig. 4. Air-exposure mortality (AEM) of juvenile large yellow croaker exposed to air for $20 \mathrm{~min}$ after being fed diets containing oxidised fish oil supplemented with vitamin $E(V E)$ for 10 weeks. Values are means, with their standard errors represented by vertical bars. ${ }^{a, b, c}$ Mean values with unlike letters were not significantly different $(P>0.05)$ among treatments. FFO, fresh fish oil; LO, lowly oxidised; $\mathrm{MO}$, moderately oxidised; $\mathrm{HO}$, highly oxidised.

effect of VE supplementation was most evident among fish receiving the $\mathrm{HO}$ diet, where a significant reduction in AEM $(P<0.05)$ was observed.

\section{Discussion}

In the present study, large yellow croaker fed diets containing oxidised fish oil without supplemental VE exhibited poor growth. This is in accordance with previous studies ${ }^{(6,26-28)}$. It was also reported that feed oxidisation decreased FI, and consequently the growth rate, of Atlantic salmon (Salmo salar) ${ }^{(29)}$. Decreases in food intake due to the presence of oxidised lipids in the diet may be the result of altered odour or palatability of the diet ${ }^{(30)}$. However, in the present study, the FI of fish was not depressed by oxidised feed, indicating that large yellow croaker tolerate quite high levels of oxidation products before they avoid the diet because of unpleasant taste or odour. This finding is in agreement with that of Hamre et al. ${ }^{(29)}$, who reported that FI in Atlantic salmon fed the oxidised diet was not significantly lower compared with fish fed the control diet. The FE was not significantly different among treatments, indicating that the oxidised fish oil was effectively absorbed. These results are in 
agreement with studies in Siberian sturgeon (Acipenser baeri $)^{(31)}$. The decreased growth of fish fed oxidised diets is likely a result of increased oxidative stress caused by both the reduced nutritional value of the diet due to the loss of HUFA $^{(32-34)}$ and the production of toxic peroxidation products $^{(28,35)}$. These mechanisms are in line with the observations from the present study, in which the activities of the two primary free-radical scavenging enzymes, CAT and SOD, were significantly increased with increasing dietary oxidised oil POV. The HSI and hepatic MDA contents were also increased with increasing dietary POV. These results clearly demonstrate that oxidised fish oil could stimulate the activities of antioxidant defence enzymes in stressed large yellow croaker and imply that fish were suffering from graded oxidative stress. Similar findings were reported in previous studies where the growth of fish fed diets containing oxidised oil was inversely proportional to the responses observed in the activities of hepatic antioxidant defence enzymes ${ }^{(8,28,36)}$

High-dose VE inclusion significantly enhanced the growth of large yellow croaker fed the oxidised oil diets in this study. This growth-promoting effect of $\mathrm{VE}$ is consistent with previous findings in tilapia ${ }^{(37)}$, grass carp ${ }^{(38)}$, Japanese flounder ${ }^{(6)}$ and gilthead sea bream $^{(8)}$. The positive effects of VE on large yellow croaker were likely due to an alleviation of the oxidative stress induced by the oxidised oil in the diet. VE can act as a scavenger of free radicals and a singlet $\mathrm{O}_{2}$ quencher ${ }^{(39,40)}$, thereby lowering the burden placed upon antioxidant enzymes. This is consistent with the observed marked decline in the activities of hepatic antioxidant defence enzymes, which suggests significant reductions in levels of oxidative stress among large yellow croaker. In accordance, hepatic MDA concentrations, HSI values and AEM of fish were lowered by dietary VE supplementation. A similar observation was reported in grass carp where hepatic MDA content was significantly decreased following supplementation with $\mathrm{VE}^{(38)}$. In the present study, VE may have also exerted beneficial effects through the enhancement of immunity in large yellow croaker. This is in accordance with the observations of significantly lower AEM of fish fed the oxidised diets supplemented with VE. Similarly, Ortuño et al. ${ }^{(41)}$ found that dietary administration of high doses of vitamins $\mathrm{C}$ and $\mathrm{E}$ reduced stress in sea bream (Sparus aurata) when exposed to a combination of stressors that included a 2-min air exposure.

It is noteworthy that the inclusion of a high concentration of dietary VE resulted in a significant decrease in the growth of fish fed the fresh oil diet in this study. This deleterious effect could potentially be caused by an excess dose of VE accumulated in the liver and other tissues ${ }^{(4,12,14,26,42,43)}$. VE stored in animal tissues is partially utilised for halting the free radical cascade initiated by lipid peroxyl radicals and other assorted products of lipid peroxidation ${ }^{(44)}$. Excess supplementation of $\mathrm{VE}$ to the biological system may lead to acceleration of lipid peroxidation, increasing accumulation of hydroperoxide in blood and reduced erythrocyte osmotic fragility of fish ${ }^{(6,16,17,45,46)}$. Moreover, high dietary concentrations of VE ( $5000 \mathrm{mg}$ of $\alpha$-Toc/ $\mathrm{kg}$ of diet) have been shown to cause reduced concentrations of erythrocytes in trout blood ${ }^{(47)}$. In addition, it was reported that an excess amount of dietary $\alpha$-tocopherol could enhance lipid deposition in fish liver ${ }^{(16)}$. Consistently, in the present study, the lipid content in the liver was increased by VE supplementation, indicating that excess VE promotes lipid accumulation, resulting in poor liver health condition in large yellow croaker. Inclusion of oxidised oil in fish diets decreased tissue $\alpha$-tocopherol concentrations $^{(7)}$. Therefore, it could be that these adverse effects of high-dose VE would be most evident in the FFO/VE group, due to a lack of reaction substrates in the form of oxidised oil supplied in the diet. Our results indicate that the degree of oil oxidation (i.e. the severity of oxidative stress) could be a key factor influencing the physiological effects of VE.

In conclusion, the ingestion of oxidised oil in the diet significantly decreased growth, but activated antioxidant defence enzymes, in large yellow croaker. Inclusion of high-dose VE supplementation can alleviate oxidative stress and enhance the immune response of stressed fish fed oxidised fish oil. However, high doses of VE can also exert deleterious effects on non- or less-stressed large yellow croaker.

\section{Acknowledgements}

The authors thank the participants who gave their time to this trial.

The study was supported by the National Natural Science Foundation of China (31302200), and the National Department Public Benefit Research Foundation (Ministry of Agriculture; 201003020).

J. W. and Q. A. designed the study. J. W. carried out most of experimental work and wrote the manuscript under the direction of the project leader Q. A., K. M. assisted in the experimental design and manuscript revision; H. X. and R. Z. carried out the rearing experiments. W. X. provided all fatty acid composition data.

The authors declare that there are no conflicts of interest.

\section{References}

1. Sargent J, Bell G, McEvoy L, et al. (1999) Recent developments in the essential fatty acid nutrition of fish. Aquaculture 177, 191-199.

2. National Research Council (2011) Nutrient Requirement of Fish and Shrimp. Washington, DC: National Academies Press.

3. Mourente G, Bell GJ \& Tocher DR (2007) Does dietary tocopherol level affect fatty acid metabolism in fish? Fish Physiol Biochem 33, 269-280.

4. Huang CH \& Huang SL (2004) Effect of dietary vitamin E on growth, tissue lipid peroxidation, and liver glutathione level of juvenile hybrid tilapia, Oreochromis niloticus $\times$ O. aureus, fed oxidized oil. Aquaculture 237, 381-389.

5. Baker RTM \& Davies SJ (2006) Changes in tissue $\alpha$-tocopherol status and degree of lipid peroxidation with varying $\alpha$-tocopheryl acetate inclusion in diets for the African catfish. Aquacult Nutr 2, 71-79.

6. Gao J, Koshio S, Ishikawa M, et al. (2014) Interactive effects of vitamin $\mathrm{C}$ and $\mathrm{E}$ supplementation on growth performance, fatty acid composition and reduction of oxidative stress in juvenile Japanese flounder Paralichthys olivaceus fed dietary oxidized fish oil. Aquaculture 422-423, 84-90. 
7. Baker RT \& Davies MSJ (1997) Modulation of tissue $\alpha$-tocopherol in African catfish, Clarias gariepinus, fed oxidized oils, and the compensatory effect of supplemental dietary vitamin E. Aquacult Nutr 3, 91-97.

8. Tocher DR, Mourente G, van der Eecken A, et al. (2003) Comparative study of antioxidant defence mechanisms in marine fish fed variable levels of oxidized oil and vitamin E. Aquacult Int 11, 195-216.

9. Mourente G, Diaz-Salvago E, Bell JG, et al. (2002) Increased activities of hepatic antioxidant defence enzymes in juvenile gilthead sea bream Sparus aurata L. fed dietary oxidized oil: attenuation by dietary vitamin E. Aquaculture 214, 343-361.

10. Martins DA, Afonso LOB, Hosoya S, et al. (2007) Effects of moderately oxidized dietary lipid and the role of vitamin $\mathrm{E}$ on the stress response in Atlantic halibut Hippoglossus hippoglossus L. Aquaculture 272, 573-580.

11. Chen YJ, Liu YJ, Tian LX, et al. (2013) Effect of dietary vitamin $\mathrm{E}$ and selenium supplementation on growth, body composition, and antioxidant defense mechanism in juvenile largemouth bass (Micropterus salmoide) fed oxidized fish oil. Fish Physiol Biochem 39, 593-604.

12. Puangkaew J, Kiron V, Somamoto T, et al. (2004) Nonspecific immune response of rainbow trout (Oncorbynchus mykiss Walbaum) in relation to different status of vitamin $\mathrm{E}$ and highly unsaturated fatty acids. Fish Shellfish Immunol 16, 25-39.

13. Lewis-McCrea LM \& Lall SP (2007) Effects of moderately oxidized dietary lipid and the role of vitamin $\mathrm{E}$ on the development of skeletal abnormalities in juvenile Atlantic halibut (Hippoglossus hippoglossus). Aquaculture 262, 142-155.

14. Lin YH \& Shiau SY (2005) Dietary vitamin E requirement of grouper, Epinephelus malabaricus, at two lipid levels, and their effects on immune responses. Aquaculture 248, 235-244.

15. Bowry VW \& Stocker R (1993) Tocopherol-mediated meroxidation-the prooxidant effect of vitamin $\mathrm{E}$ on the radicalinitiated oxidation of human low-density-lipoprotein. J Am Chem Soc 115, 6029-6044

16. Tokuda M \& Takeuchi M (1995) Effects of excess doses of $\alpha$-tocopherol on the lipids and function of rainbow trout liver. J Nutr Sci Vitaminol 41, 25-32.

17. Ito T, Murata H, Tsuda T, et al. (1999) Effects of $\alpha$-tocopherol levels in extrusion pellets on in vivo lipid peroxidation levels and antioxidant activities in cultured yellow tail Seriola quinqueradiata injected with the causative bacteria of fish jaundice. Fish Sci 65, 679-683.

18. Tocher DR, Mourente G, van der Eecken A, et al. (2002) Effects of dietary vitamin $\mathrm{E}$ on antioxidant defence mechanisms of juvenile turbot (Scophthalmus maximus), halibut (Hippoglossus hippoglossus) and sea bream (Sparus aurata). Aquacult Nutr 8, 195-207.

19. Gao J, Koshio S, Ishikawa M, et al. (2013) Interactive effects of vitamin $\mathrm{C}$ and $\mathrm{E}$ supplementation on growth, fatty acid composition, and lipid peroxidation of sea cucumber, Apostichopus japonicus, fed with dietary oxidized fish oil. $J$ World Aquacult Soc 44, 536-546.

20. Wang J, Ai Q, Mai K, et al. (2014) Dietary chromium polynicotinate enhanced growth performance, feed utilization, and resistance to Cryptocaryon irritans in juvenile large yellow croaker (Larmichthys crocea). Aquaculture 432, 321-326.

21. Zhang L (2006) Nutritional physiology of several vitamins and protein sources development for Japanese sea bass Lateolabrax japonicus and large yellow croaker, Pseudosciaena crocea. PhD Thesis, Ocean University of China, Qingdao.
22. Association of Official Analytical Chemists (1995) Animal feed. In Official Methods of Analysis, 16th ed., pp. 1-45 [P Cunniff, editor]. Arlington, VA: AOAC.

23. Folch J, Lees M \& Sloane Stanley GH (1957) A simple method for the isolation and purification of total lipides from animal tissues. J Biol Chem 226, 497-509.

24. Zuo R, Ai Q, Mai K, et al. (1999) Effects of conjugated linoleic acid on growth, non-specific immunity, antioxidant capacity, lipid deposition and related gene expression in juvenile large yellow croaker (Larmichthys crocea) fed soyabean oil-based diets. Br J Nutr 110, 1220-1232.

25. Salo-Väänänena $\mathrm{P}$, Ollilainen $\mathrm{V}$, Mattila $\mathrm{P}$, et al. (2000) Simultaneous HPLC analysis of fat-soluble vitamins in selected animal products after small-scale extraction. Food Chem $\mathbf{7 1}$, 535-543.

26. Peng S, Chen L, Qin JG, et al. (2009) Effects of dietary vitamin E supplementation on growth performance, lipid peroxidation and tissue fatty acid composition of black sea bream (Acanthopagrus schlegeli) fed oxidized fish oil. Aquacult Nutr 15, 329-337.

27. Dong GF, Huang F, Zhu XM, et al. (2012) Nutriphysiological and cytological responses of juvenile channel catfish (Ictalurus punctatus) to dietary oxidized fish oil. Aquacult Nutr 18, 673-684.

28. Fontagné-Dicharry S, Lataillade E, Surget A, et al. (2014) Antioxidant defense system is altered by dietary oxidized lipid in first feeding rainbow trout Oncorbynchus mykiss. Aquaculture 424-425, 220-227.

29. Hamre K, Kolas K, Sandnes K, et al. (2001) Feed intake and absorption of lipid oxidation products in Atlantic salmon Salmo salar fed diets coated with oxidized fish oil. Fish Physiol Biochem 25, 209-219.

30. Simic MG \& Karel M (1980) Autoxidation in Food and Biological Systems. New York, NY: Plenum Press.

31. Fontagné S, Bazin D, Brèque J, et al. (2006) Effects of dietary oxidized lipid and vitamin A on the early development and antioxidant status of Siberian sturgeon Acipenser baeri larvae. Aquaculture 257, 400-411.

32. Lingenfelser JT, Blazer VS \& Gay J (1995) Influence of fish oils in production catfish feeds on selected disease resistance factors. J Appl Aquacult 5, 37-48.

33. Sánchez-Muniz FJ, López-Varela S, Garrido-Polonio MC, et al. (1998) Dietary effects on growth, liver peroxides, and serum and lipoprotein lipids in rats fed a thermoxidised and polymerised sunflower oil. J Sci Food Agric 76, 364-372.

34. Koven W, Barr Y, Lutzky S, et al. (2001) The effect of dietary arachidonic acid (20:4n-6) on growth, survival and resistance to handling stress in gilthead sea bream Sparus aurata larvae. Aquaculture 193, 107-122.

35. Matés JM, Pérez-Gómez C \& Castro IND (1999) Antioxidant enzymes and human diseases. Clin Biochem 32, 595-603.

36. Hwang DF, Hour JL \& Cheng HM (2000) Effect of taurine on toxicity of oxidized fish oil in rats. Food Chem Toxicol 38, 585-591.

37. Shiau SY \& Shiau LF (2001) Re-evaluation of the vitamin E requirements of juvenile tilapia (Oreochromis niloticus $\times$ O. aureus). Anim Sci 72, 529-534

38. Li J, Liang XF, Tan QS, et al. (2014) Effects of vitamin E on growth performance and antioxidant status in juvenile grass carp Ctenopharyngodon idellus. Aquaculture 430, 1-27.

39. Cay PB \& King MM (1980) Vitamin E: its role as a biological free radical scavenger and its relationship to the microsomal mixed function oxidase system. In Vitamin $E, A$ Comprehensive Treatise: Basic and Clinical Nutrition, pp. 289-317 [LJ Machlin, editor]. New York: Marcel Dekker. 
40. Gunstone F (1996) Fatty Acid and Lipid Chemistry. London: Blackie Academic and Professional.

41. Ortuño J, Esteban MA \& Meseguer J (2003) The effect of dietary intake of vitamins $\mathrm{C}$ and $\mathrm{E}$ on the stress response of gilthead sea bream (Sparus aurata). Fish Shellish Immunol 14, 145-156

42. Ruff N, Fitzgerald RD, Cross TF, et al. (2003) The effect of dietary vitamin $\mathrm{E}$ and $\mathrm{C}$ level on market-size turbot (Scophthalmus maximus) fillet quality. Aquacult Nutr $\mathbf{9}$, 91-103.

43. Gao J \& Koshio S (2015) Effect of dietary lipid oxidation with vitamin $\mathrm{C}$ and $\mathrm{E}$ supplementation on fillet quality of red sea bream, Pagrus major (Temminck \& Schlegel) during storage. Aqua Res 46, 2382-2391.
44. Sheehy PJA, Morrissey PA \& Flynn A (1994) Consumption of thermally-oxidized sun-flower oil by chicks reduces alphatocopherol status and increases susceptibility of tissues to lipid oxidation. Br J Nutr 71, 53-65.

45. Tokuda M \& Takeuchi M (1999) Effects of excess doses of $\alpha$-tocopherol on the lipid in serum and muscle of rainbow trout. Fish Sci 65, 496-497.

46. Kaewsrithong J, Ohshima T, Ushio H, et al. (2001) Effects of an excess dose of dietary $\alpha$-tocopherol on hydroperoxide accumulation and erythrocyte osmotic fragility of sweet smelt Plecoglossus altivelis. Aqua Res 32, 191-198.

47. Poston HA \& Livingston DL (1969) Effects of massive doses of dietary vitamin $\mathrm{E}$ on fingerling brook trout. Fish Res Bull NY State Conserv Dep 33, 9-12. 